\title{
Children's Concepts of How the Digestive System Works
}

\author{
Adriana Wiegerováa*, Hana Navrátilová ${ }^{b}$, Andrea Dalajková ${ }^{c}$ \\ * Corresponding author: Adriana Wiegerová, wiegerova@fhs.utb.cz \\ ${ }^{a}$ Faculty of Humanities, Tomas Bata University in Zlin, Czech Republic, wiegerova@fhs.utb.cz \\ ${ }^{b}$ Faculty of Humanities, Tomas Bata University in Zlin, Czech Republic, hnavratilova@fhs.utb.cz \\ ${ }^{c}$ Faculty of Humanities, Tomas Bata University in Zlin, Czech Republic
}

\begin{abstract}
http://dx.doi.org/10.15405/epsbs.2016.11.27

This study presents the findings in the concepts of preschool children about the human digestive system. The research is based on qualitative approach with analysis of children's drawings and interviews and it includes a group of 18 five to six-year-old children. Through the significant findings comparing to older studies on the concepts of the digestive system, the authors discuss the changes in concepts of today's children. The aim of the study is also to identify the possibilities of working with children's concepts from the position of a preschool teacher and to provide basic suggestions for the application of appropriate didactic strategies for preschool teachers in kindergartens.
\end{abstract}

(C) 2016 Published by Future Academy www.FutureAcademy.org.uk

Keywords: Children's concepts; preschool teacher; didactic strategies; preschool children.

\section{Introduction}

In order to discuss the changes in children's concepts, it is necessary to present theoretical background related to the actual perception of children's creation of phenomena concepts and to give the examples of concepts of the digestive system by preschool children. These concepts are explained via analysis of children's drawings and interviews.

Children begin to explore their closest surroundings at a very early age. All stimuli around them allow them to create their specific concepts related to the environment and to the world around them. These concepts - called children's concepts - represent children's understanding of the world that is based on their own experience. A child's understanding of the world is very specific and it is important 
to realise that it usually varies from adults' understanding. Currently discussed conception of children and childhood is characterised by the fact that we no longer perceive the child as an "unfinished adult." We accept children's reactions to phenomena as complete, perfect and clear at all stages in life. The factors affecting their concepts can be exogenous and endogenous. Among the exogenous factors we count for example social, economic, ethnic, cultural and religious influences. The endogenous factors are influenced by individual, psychological and biological prerequisites of each child, and they are developed on the basis of exogenous factors.

\subsection{Research on the Human Digestive System in Children's Concepts}

We can find various $20^{\text {th }}$ century conceptions on childhood that relate to our research, as children's thinking and its gradual development had been mapped for a century by psychologists, educationalists and sociologists (J. Piaget, L. S. Vygotski, J. Bruner, D. P. Ausubel, F. J. Dochy etc.) In recent years, however, the agency theory (Kehily, 2009) has also influenced the theory of the development of child's world perceptions, which presents the main changes in children's ability to describe the world and explains children's accelerated development nowadays that is caused by a wider range of possibilities to access information.

Several authors have written studies focused on research of children's concepts about the human body. Pupala and Osuská (1997) used a method called “conceptual mapping” to examine children's concepts about the digestive system. Their research sample included 206 children from which 34 were preschool children. They always started interviewing the children with the same initial question about what was happening inside the children's bodies. Such a research method is similar to the one we used in our study, as our method consisted of both the interviews and the analysis of children's drawings. The most significant point Pupala and Osuská make in their research is that children have the tendency to personify the stomach; for example, a six-year-old child compared its activity of food processing to the work of manual workers.

The studies by E. Gellert (1962), C. S. Porter (1976) and E. C. Smith (1977) discussed the issue of a child's ability or inability to identify and describe the phenomena and they also brought the findings about at what age the children start using the terminology related to human body. M. H. Nagy (1953) presented the results of three surveys of children in different age groups and from various backgrounds (Hungary, England and the USA) with the aim to determine the concept of the digestive processes on the basis of the question of what happens to the food we consume. The above mentioned studies (and not only those, but many others) agreed that children are unable to describe the particular parts of digestive system before they reach the age of 12 .

However, our research brings contradictory findings. As we will demonstrate, a child as young as 5 is able to describe the internal processes in the human body - in our case the digestive system. Discussions should take into consideration that the children nowadays are better informed, they have more experience and therefore they are able to provide more detailed descriptions already at a very young age. 


\section{Research methods}

The aim of the research was to determine children's concepts about the human digestive system. When determining children's concepts, the researcher has to take into account such factors as incomprehensibility of speech, emotional stability and other issues. Gavora (2010) is of the opinion that when investigating child's concepts, it is necessary to talk to the child without using scientific terms at first. Only when the child himself/herself uses specific terminology, can we continue to build on it.

We selected two research methods to work with the research subjects - children's drawings and interviews.

The research subjects were all preschool children. We worked with eighteen children whose age ranged between 5 (twelve children) and 6 (six children). There were eleven boys and seven girls in the group. All the children attended the same class in a kindergarten in the Zlín region.

Once the data was collected and processed, we proceeded to analyse it on the basis of the so-called recursive reading. We also applied the principle of induction to the research. The benefit of this principle was to provide a potentially new perspective on the researched phenomenon or phenomena.

\subsection{Samples of Interviews and Drawings of the Digestive System by Preschool Children}

As mentioned above, we used the combination of two methods of data collection. With all 18 children we first arranged the drawings and then matched them with children's interviews. In many cases, children provide explanations they are not able to put down on paper. Therefore, we consider the oral descriptions in the form of interviews extremely important. The age and the chosen pseudonym of each child is written on the pictures.

As an example, we provide the results of the drawings of two five-year-old boys, where we can observe noticeable differences in both drawings. Then we also present an example of the interview conducted with one of these boys - Petr.

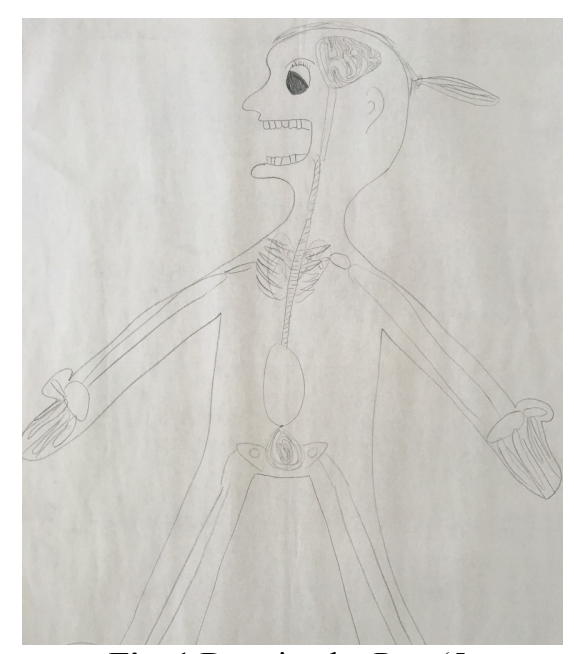

Fig. 1 Drawing by Petr (5 years old)

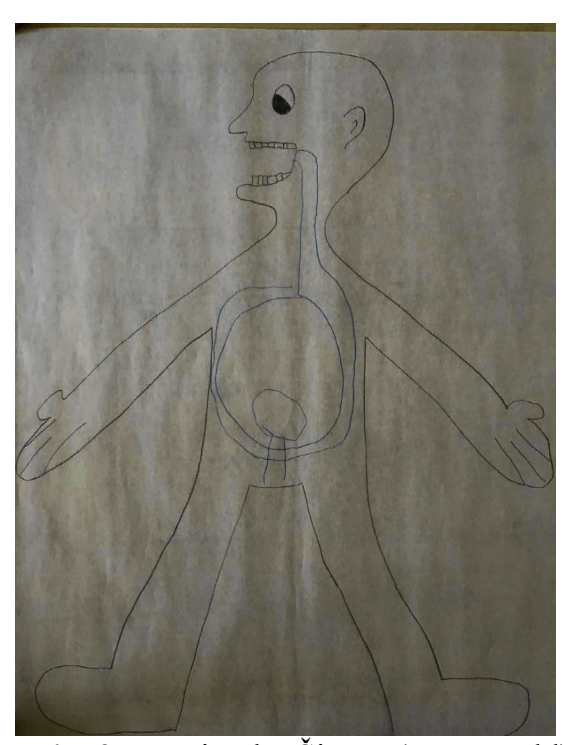

Fig. 2 Drawing by Šimon (5 years old) 
Petr created a unique drawing not only of the digestive system but of the whole body. Šimon's drawing corresponds with his explanation of how food is processed when he used the term "intestine." After being asked about his idea of the intestines being a part of our body, he drew the system of intestines in a circle, with stomach inside, and with "tubes" which serve for the excretion.

When Petr saw the contour of the human body, he first identified it as a girl, explaining the recognizable signs (eyebrows, long hair). Petr was then asked the initial question: what he thinks happens to the apple when he eats it. Without hesitation he replied: "It is digested. Right, and how is it digested? In the stomach." When we asked him how the apple reaches the stomach, his interpretation suggested the structure of the esophagus: "It slips through this hole into the stomach. It slips through a hole, right. Yeah, through this tube is gets into the stomach. And the stomach is like this (pointing to his own body)." Then we asked him to draw it and he agreed with a smile. He began by drawing two vertical lines leading from the mouth to approximately halfway of the abdominal cavity. He added an oval shape which he called stomach. We asked him if the tube continued somewhere else from the stomach. He began to explain his ideas of excretion: "Yeah, here (he points to the bottom part of the abdominal cavity on his picture). But if you have a drink, then you need to pee. Right, when I have a drink then I need to pee. And so it goes through the stomach? Yeah."

We followed up on his answer with the question of how food can get out of the stomach, or how we can urinate or defecate. He thought for a while, "Hm, well, I still ..." and he said that all information is in his books at home, so he does not know it exactly. After a moment's thought, he replied: "I think that here there's a hole. Poo goes through this hole and pee through this one. And here there's a string ... Well, or they are together." Suddenly, he produced a surprising concept: "Here are the lungs."

All by himself he realized that lungs appear in a different place in the body and corrected himself: "No, no, they are somewhere else ... They are here." He began to think and exclaimed: "It's the intestines. I couldn't remember." He then added that from the intestines the apple goes into the toilet.

Even from these short interview excerpts it is obvious that preschool children have accelerated understanding of the world around them and that they are able to identify the objects much more quickly in comparison to older research studies mentioned earlier. All 18 interviews based on the drawings proceeded in a similar way. The one factor which was common to all children was their ability to refer to some parts of human body with specialist terminology. They all recalled a film, a fairy tale or a book in which they had heard or seen something about the digestive system. Some children also reported seeing the digestive system on the computer or tablet.

\section{Research findings: Summary of children's concept about the functioning of the digestive system}

On the basis of children's testimonies we were able to distinguish the following main categories:

- $\quad$ Person or doll

- $\quad$ From mouth onwards

- $\quad$ Food storage

- How it goes out 
http://dx.doi.org/10.15405/epsbs.2016.11.27

eISSN: 2357-1330 / Corresponding Author: Adriana Wiegerová

Selection and peer-review under responsibility of the Organizing Committee of the conference

The categories are interconnected because they are based on children's perception of the digestive system.

- Person or doll

In front of them, the children had a piece of paper with the outline of a human body. Most frequently, the children answered the first question, "Do you recognize what's in the picture?" with the following replies: “Yeah. It's a person." (Martin), “It's simply a person." (Jakub), "It's the figure of a person." (Eva). Apart from the identification of a person, we also recorded answers such as: "A doll”, (Liliana), "The figure of a doll." (Vitek).

- From the mouth onwards

We asked the children what they think happens to an apple when they eat it. The most common replies were: "It falls into the belly." (Martin); "It fell into the belly." (Jakub), "It went down to the belly (Vitek)", “It flies to the belly." (Lucie), "It went to the belly." (Daniel), "It goes to the belly (Šimon), "It disappears into the body. Into the belly." (Adéla).

Some children began by referring to the function of teeth in the mouth: "Well, we eat it with our teeth and then it goes into the belly."(Radek). "Well, we eat it in the mouth." (Silva), "It stayed in the mouth." It stayed in the mouth, right. Does it go any further? It's ... in the body. Right, in the body. And how did it get there, in the body? Down. Into the belly.(Tobias)

In some of the replies given by the subjects we could see some references the esophagus: "There is a little tube." “Well, it goes through some little ways."(Liliana), "It's such a little tube.”(Žaneta), “It's such a tube.” (Šarlota), “Well, it goes through such a red tube.” (Alex), "Through here, the throat." (Lucie), "Through this little tube it gets to the stomach." At the end of the interview, one of the participants mentioned once again the "little tube" with this extra information: "This is also a bone. Well, it is the tube food goes through, but inside it there are bones. "(Petr).

Within this category we can also detect the term stomach in some replies: "It falls into the stomach." (Martin), "It slips through this hole into the stomach." (Petr), "It dissolves in the body. In the stomach." (Žaneta), "It falls into the stomach." (Eva), "It falls here,... there is the stomach."(Silva).

A very interesting case was that of the boy who knew the term intestines, but he placed them before stomach: "It goes to the belly. And how does the apple get from the mouth to the belly? Well, ... through the intestines. Right, through the intestines to the belly. And straight to the stomach." (Šimon).

The twin's concept was also interesting, especially because they both gave a similar reply to the question: "It is digested ... in the stomach." (Petr), "Well, we eat it in the mouth and then it is digested." (Jiři). Here we can notice the use of a special term - stomach.

A little girl had a similar remarkable idea, even if less realistic, when she said: "They run around here, they are blue and they have little tails on their heads. There are four paths and every day they walk down one of the paths. They deliver the news there."(Liliana)

- Food storage 
In this category we distinguished children's concepts about how food is stored and which processes take place in the abdominal cavity during digestion.

At first, the children described where food goes: "Into the belly. There it's all gathered together." (Adéla), "And it goes into the belly, ... and there it is with other food." (Jakub). In the following replies, we hear more often the term stomach: "It falls into the stomach, ... there is this ugly water. Sort of green. It's in the stomach.” (Martin), "It falls into the stomach. Here's the apple and here's the stomach.” (Eva), “Well, it went into the stomach and then it went into the belly.” (Daniel), “... it gets to the stomach.” (Šimon), "There is the stomach, ... there is all the food, ... it is all together." (Silva), “Well, it's all simply in the stomach.” (Alex), “... and here is the stomach.” (Žaneta).

The children's concepts of where food goes were connected with the processes which could possibly take place: "It goes down there and from drink there's the green water. But it is without normal water. It swims there, there are some small pieces and there it dissolves." (Martin), "And it becomes a kind of liquid. Right, and how does such a liquid form? All food gets dissolved there." (Eva), “It works there.” (Lucie), “... somehow it's sorted out.”(Kuba).

At this point, some children's concepts about the digestive system ended here: "Food. An apple, for example, and it's there together with other food." (Jakub), "It's there together." (Vitek), “Well, it falls down, down and then completely down. Right, and what happens to it down there? Well, nothing, I don't know. It stays there.' (Kuba), “Well, it stays there, ... it's always there.” (Šarlota).

Two boys, the twins, both worked with the term digestion, but described it in different ways. The first boy described digestion as follows: "It is digested. It slips through this hole into the stomach, through this little tube it gets to the stomach. And the stomach is like this." (Petr). On the contrary, the other boy did not work at all with the term stomach: "It is digested. Right, and where is it digested? In the tonsils, ... then it is digested, here nearby, ... it is digested in the belly. It's like when you eat some bread, it's broken up into small pieces, here, ... and it is then digested, ... some other day I digest it, ... I have to wait, and when I eat a lot, then I have to wait longer." (Jiři).

A little girl, who confused the Czech word for stomach with the Czech word for acorn (TN: in Czech the two words are 'žaludek' and 'žalud'), had a remarkable concept of food storage: “Then it goes into the belly. Right, and how does it get into the belly? Through the acorn. Right, and could you draw it? Yeah, here this way to the acorn (she draws an acorn - the fruit of the oak). There it is mixed together. And does it continue somewhere else? Into the belly." (Šarlota).

In some statements, it is obvious that children must have heard something about the concepts, but then they could not describe them. This point also proves that today's pre-schoolers have a lot of information.

\section{- How it goes out}

This category reflects how the subjects represent defecation or evacuation in general. The ideas of some of the participants are not referred to in this paper since they spoke about food being stored in the body and not going anywhere else. On the other hand, the second half of the participants continued with ease where the previous category finished.

Three of them even connected the term "stomach" with the term "intestines" or described the structure of the intestines orally: "Well,... the intestines. They are kinds of knots and it goes into them." 
(Alex), "I think that here there is a hole. Through this hole the poo comes out and through here comes the pee. And here is this string. Well, or here they are together. Here are the lungs. Lungs, right. No, no, they are somewhere else ... They are here ... These are the intestines. I couldn't remember." (Petr), "They have got a way through which they go into the toilet. They create them." (Silva), "Well, the little tube continues there." (Žaneta), "And does it go somewhere else from the stomach? To the bottom. Right, and how does it get from the stomach to the bottom? I don't know, ... now I know, through a tube, here, like this, ... and then it is in the bottom and it goes into the toilet." (Šimon), "There is a way for that ... And everything goes there and then we have to pee." (Tobias)

Most children described defecation directly. According to the participants, it happens in different ways and for different reasons: "It goes further down. But when we go to the toilet, then it's the food." (Martin), "Well, the food it doesn't want, becomes poo, and the drink it doesn't want, becomes pee. And what if the body wants the food? Then it leaves it there, ... then it sorts it out." (Šarlota), "... it is all collected together, ... and when there is a lot, then we make a poo." (Adéla), "It's like when we've drunk a lot of juice or we have a full belly and need to go to the toilet, ... and when the belly doesn't need something, then it goes to the toilet and makes a poo or pee." (Radek), "This then creates, ... then this becomes ... poo, ... it all goes away." (Eva), "But if something isn't good, then we make a poo." (Žaneta), "And then we simply make a poo."(Alex). "But when you drink, for example, then you pee. And when we eat something, well, then we make a poo." (Petr).

The ideas of those participants who describe simultaneously evacuation and vomiting are also interesting: "Or if we are sick and overeat, then it's also the food, ... the air pushes it up to the top." (Martin), "But when we want to vomit, then our belly hurts because we've eaten a lot, ... I ate a lot of food and then I was sick and my belly hurt." (Alex), "Or when we feel bad, we have to be sick. ... I ate too much food." (Tobias). One boy didn't even mention evacuation at all, he only described vomiting: "And what isn't healthy, comes up to to the top and he spits it out. And what if it's healthy? When it's healthy, we digest it." (Jiři).

\section{Conclusion}

On the whole, we can say that preschool children divide the digestive system into three parts as we could see in the main categories described above.

- Children's concepts about how food gets from the mouth to the body.

After speaking first about the "falling" of the food somewhere down, children started to use the term "tube" (also "little tube", sometimes "little ways") in the course of the interview and drawing. Their concept of the "tube" then became a part of the drawing and it indicates the existence of the preconcept of the esophagus. Some children, however, began with the oral cavity by mentioning the function of teeth which proves their comprehensive concept that the digestive system begins in the oral cavity and that the teeth play a significant role.

- Children's concepts called food storage. 
The first half of the participants describes that food is stored in the "belly" but the second half works with the term stomach already at preschool age. We can make a comparison with the researches of $E$. Gellert (1962), C. S. Porter (1974), E. C. Smith (1977) (see chapter 1.1). Although these studies had been conducted 40 years ago, we should take into consideration the noticeable shift when it comes to the usage of these terms in children's concepts about digestive system. Some participants ended their description of the whole system with stomach because they said that food remains in the abdominal cavity, and it either dissolves or accumulates there.

- $\quad$ Children's concepts about excretion called how it goes out.

Some participants began to describe the process of vomiting and its causes spontaneously. The majority focused directly on evacuation. The most significant finding was again based on the children's usage of a specific term "intestines". Comparing it to study by Pupala and Osuská (1997), their participants used common colloquial terms to refer to the exit part with personification, while the older children often mistook it for the bladder, but they never used the term "intestines."

We can state that there has been a significant shift in children's concepts because today's children, including pre-schoolers, have more realistic concepts about the digestive system. The participants who described their ideas in a comprehensive and detailed way also reported their sources of information. They often cited books, but also fairy tales and television programmes, they definitely have a better access to information that influences their concepts. But we also found out that the children derive their concepts about the digestive system from the home environment, and never from kindergarten.

Since compulsory education at the kindergarten level for pre-schoolers aged 5 will soon be introduced in the Czech Republic, children's ideas should be respected and teachers should learn about them. They must know how to work with them and not to be surprised when a child already uses such terms as "stomach" or "intestines." As a result, teachers working in kindergartens should support the children in spontaneous learning about the digestive system, the entire human body and other phenomena which surround the children.

\section{References}

Gavora, Peter. (2010) Úvod do pedagogického výzkumu. Brno: Paido, 261.

Gellert, Elizabeth. (1962) Children's conceptions of the contect and functions of the human body. Genetics Psychology Monograph, 65, 1962, 293-405.

Kehily, M. J. (ed.) (2009) An introduction to childhood studies. Maidenhead: Open University Press. Nagy, Maria H. (1953) Children's conceptions of some bodily functions. The Pedagogical Seminary and Journal of Genetic Psychology, 83, 1953, 199-216.

Pupala, B. \& Osuská. L. (1977) vývin detských koncepcií o tráviacej sústave a trávení. Psychológia a patopsychológia diet'at'a, 1997, 1, 35-46. 32. 